\title{
Incidence, causes, and maternofetal outcomes of obstructed labor in Ethiopia: systematic review and meta-analysis
}

Asteray Assmie Ayenew*

\begin{abstract}
Background: Obstructed labor is a preventable obstetric complication. However, it is an important cause of maternal mortality and morbidity and of adverse outcomes for newborns in resource-limited countries in which undernutrition is common resulting in a small pelvis in which there is no easy access to functioning health facilities with a capacity to carry out operative deliveries. Therefore, this systematic review and meta-analysis aimed to estimate the incidence, causes, and maternofetal outcomes of obstructed labor among mothers who gave birth in Ethiopia.

Method: for this review, we used the standard PRISMA checklist guideline. Different online databases were used for the review: PubMed, Google Scholar, EMBASE, Cochrane Library, HINARI, AFRO Library Databases, and African Online Journals. Based on the adapted PICO principles, different search terms were applied to achieve and access the essential articles. The search included all published and unpublished observational studies written only in the English language and conducted in Ethiopia. Microsoft Excel 16 was used for data entrance, and Stata version 11.0 (Stata Corporation, College Station, Texas, USA) was used for data analysis.
\end{abstract}

Results: I included sixteen (16) primary studies with twenty-eight thousand five hundred ninety-one $(28,591)$ mothers who gave birth in Ethiopia. The pooled incidence of obstructed labor in Ethiopia was 12.93\% (95\% Cl: 10.44-15.42, $\left.\mathrm{I}^{2}=98.0 \%, p<0.001\right)$. Out of these, $67.3 \%$ (95\% Cl: 33.32-101.28) did not have antenatal care follow-up, $77.86 \%$ (95\% $\mathrm{Cl}$ : 63.07-92.66) were from the rural area, and $58.52 \%$ (95\% Cl: 35.73- 82.31) were referred from health centers and visited hospitals after $12 \mathrm{~h}$ of labor. The major causes of obstructed labor were cephalo-pelvic disproportion 64.65\% (95\% Cl: $57.15-72.14$ ), and malpresentation and malposition in $27.24 \%$ (95\% Cl: 22.05-32.42) of the cases. The commonest complications were sepsis in 38.59\% (95\% Cl: 25.49-51.68), stillbirth in 38.08\% (95\% Cl: 29.55-46.61), postpartum hemorrhage in $33.54 \%$ (95\% Cl:12.06- 55.02), uterine rupture in 29.84\% (95\% Cl: 21.09-38.58), and maternal death in $17.27 \%$ (95\% Cl: 13.47-48.02) of mothers who gave birth in Ethiopia.

Conclusion: This systematic review and meta-analysis showed that the incidence of obstructed labor was high in Ethiopia. Not having antenatal care follow-up, rural residency, and visiting hospitals after $12 \mathrm{~h}$ of labor increased the incidence of obstructed labor. The major causes of obstructed labor were cephalo-pelvic disproportion, and malpresentation and malpresentation. Additionally, the commonest complications were sepsis, stillbirth, postpartum hemorrhage, uterine rupture, and maternal death. Thus, promoting antenatal care service utilization, a good referral system, and availing comprehensive obstetric care in nearby health institutions are recommended to prevent the incidence of obstructed labor and its complications.

*Correspondence: amanuelbiruk0077@gmail.com

Midwifery Department, College of Medicine and Health Sciences, Bahir

Dar University, Bahir Dar, Ethiopia original author(s) and the source, provide a link to the Creative Commons licence, and indicate if changes were made. The images or other third party material in this article are included in the article's Creative Commons licence, unless indicated otherwise in a credit line to the material. If material is not included in the article's Creative Commons licence and your intended use is not permitted by statutory regulation or exceeds the permitted use, you will need to obtain permission directly from the copyright holder. To view a copy of this licence, visit http://creativecommons.org/licenses/by/4.0/. The Creative Commons Public Domain Dedication waiver (http://creativeco mmons.org/publicdomain/zero/1.0/) applies to the data made available in this article, unless otherwise stated in a credit line to the data. 
Keywords: Obstructed labor, Obstetric complications, Maternal mortality and morbidity, Systematic review and meta-analysis, Ethiopia

\section{Plain english summary}

Labor is considered obstructed when the presenting part of the fetus cannot progress into the birth canal, despite strong uterine contractions. The most frequent cause of obstructed labor is cephalo- pelvic disproportion, a mismatch between the fetal head and the mother's pelvic brim. The fetus may be large to the maternal pelvic brim, such as the fetus of a diabetic woman, or the pelvis may be contracted, which is more common when malnutrition is prevalent. Some other causes of obstructed labor may be malpresentation and malposition of the fetus (shoulder, brow, or occipito- posterior positions). In rare cases, locked twins or pelvic tumors can cause obstruction. To the best of my knowledge, no systematic review was conducted to estimate the national prevalence of obstructed labor. Therefore, this systematic review and meta-analysis aimed to estimate the incidence, causes, and maternofetal outcomes of obstructed labor among mothers who gave birth in Ethiopia. Sixteen (16) primary studies with twenty-eight thousand five hundred ninety-one $(28,591)$ mothers who gave birth in Ethiopia were included. The pooled incidence of obstructed labor) mothers who gave birth in Ethiopia was $12.93 \%$. Out of these, $67.3 \%$ did not have antenatal care follow-up, $77.86 \%$ were from the rural range, and $58.52 \%$ were referred from health centers and visited hospitals after at least $12 \mathrm{~h}$ of labor. The major causes of obstructed labor were cephalo-pelvic disproportion $64.65 \%$, and malpresentation and malposition in $27.24 \%$ of the cases. The commonest complications were sepsis in $38.59 \%$, stillbirth in $38.08 \%$, postpartum hemorrhage in $33.54 \%$, uterine rupture in $29.84 \%$, and maternal death in $17.27 \%$ of mothers who gave birth in Ethiopia. Thus, promoting antenatal care service utilization, a good referral system, and availing comprehensive obstetric care in nearby health institutions are recommended to prevent the incidence of obstructed labor and its complications.

\section{Introduction}

Obstructed labor is defined as a failure of the fetal presenting part to descent in the birth canal due to mechanical reasons, despite having adequate uterine contraction $[1,2]$. It is diagnosed when the duration of labor is prolonged, a laboring mother became unable to support herself or unable to move her lower extremities, with deranged vital signs, distended bladder, Bandle's ring formed in the lower uterine segment, fetal distress or death, edematous vulva, big caput, significant molding, foul-smelling and thick meconium-stained amniotic fluid [3]. Neglected obstructed labor (OL) is a major cause of both maternal and newborn morbidity and mortality. The obstruction can only be alleviated by means of operative delivery, either cesarean section or other instrumental delivery (forceps, vacuum extraction, or simphysiotomy) [4].

Globally, at least 585,000 women die each year from complications of pregnancy and childbirth. More than $70 \%$ of all maternal death is due to five major complications: hemorrhage, infection, unsafe abortion, hypertensive disorders of pregnancy, and obstructed labor [5]. Among these etiologies, obstructed labor is one of the most common causes of maternal illness and death in sub-Saharan Africa and Southeast Asia. Worldwide, obstructed labor occurs in an estimated $5 \%$ of pregnancies and accounts for an estimated $8 \%$ of maternal deaths. The majority of the maternal deaths occurred in the poor, illiterate, hard-to-reach women who are living in rural areas with limited or no access to skilled birth attendants [6].

It is an indicator of inadequacy and poor quality of obstetric care, and immediate cause of maternal and prenatal morbidity and mortality due to uterine rupture, complications of cesarean delivery, postpartum hemorrhage, anesthesia complications, puerperal sepsis, asphyxia, and brain damage. Moreover, neglected obstructed labor resulted from poverty and prohibiting high cost of maternal care in hospitals, ignorance, illiteracy, obstructed transportation, socio-cultural belief to achieve vaginal delivery at all cost, late referrals, and aversion to caesarean delivery and hospital delivery especially after a previous caesarean operation [7].

The fetus dies first, followed by the death of the mother that puts the lives of other children in the family in jeopardy. Many parturient women die undelivered and delivered by postmortem cesarean delivery [8]. The few women with intra uterine infection and fetal deaths that managed to reach the hospital alive, the tip of the iceberg, were usually delivered by cesarean operations because of lack of the skills to perform the simpler fetal destructive vaginal operations, and this is associated with the gamut of complications $[5,9]$. The risk of maternal death after abdominal delivery in such a septic condition can be very high [10].

Other complications of abdominal delivery include sepsis and septic shock, anemia, blood transfusion, wound infection, and burst abdomen, prolonged hospital 
stay, high cost of care, infertility, aversion to hospital delivery, and caesarean delivery in a subsequent pregnancy, obstetric fistulas, abandonment, and even divorce. Complications that have been attributed directly to fetal destructive vaginal operations include uterine rupture in $2.6-9.1 \%$ of cases, postpartum hemorrhage in $4.5 \%$, and cervical and vaginal lacerations in 1.3\% [11].

Maternal mortality arising from destructive operations in the management of neglected obstructed labor ranged from 0 to $2.7 \%$ when compared to $7.5 \%$ for abdominal delivery $[11,12]$. Certainly, fetal destructive operation is safer than abdominal delivery in neglected obstructed labor with fetal demise provided the uterus has not ruptured and is not at the verge of rupture.

Maternal and perinatal mortality and morbidity associated with obstructed labor are almost totally prevented in developed countries because of improved nutritional status, wide health coverage, adequate transportation and communication system, availability of trained health personnel, optimal antenatal and intrapartum care, and other related factors [13].

In most sub-Saharan countries including Ethiopia, women are traditionally expected to give birth at home and consequently delay their health care seeking in childbirth, even if complications arise. Moreover, women are often marginalized in decision making regarding where and when to seek care [14]. Unofficial financial demands from health workers prevent women from badly needed maternal health services. Inadequately developed health care systems including poor infrastructure, poor transportation and poor obstetric services are also major contributors to obstructed labor [15].

Obstructed labor has different magnitudes in different developing countries ranging from 2 to $8 \%$. When we come to Africa some research finding showed that the magnitude of obstructed labor was more than the above determined once; In Uganda and Ethiopia, the magnitude of obstructed labor was described as $10.5 \%$ and $12.2 \%$ respectively $[2,16]$. In Ethiopia, despite different strategies to reduce morbidities and mortalities, among the 412 maternal deaths per 100,000 live births annually, 19.1\% happened due to obstructed labor $[17,18]$.

Apart from maternal deaths, obstructed labor had different maternal outcomes such as uterine rupture, postpartum hemorrhage, puerperal sepsis, bladder injury, Vesico-Vaginal fistula (VVF), recto-vaginal fistula (RVF), and fetal outcomes including birth asphyxia, stillbirth, neonatal jaundice, and umbilical sepsis [3, 19, 20]. By far, the most severe and distressing long-term condition following obstructed labor is obstetric fistula which causes serious social issues of divorce, separation from religious exercises, detachment from their families which can worsen poverty, and malnutrition [20]. Despite these severe complications, the prevalence of obstructed labor is still high in Ethiopia ranging from 3.3\% in Tigray region [21] to $34.3 \%$ in Oromia region [22]. Therefore, the aim of this systematic review and meta-analysis was to estimate incidence, causes, and maternofetal outcomes of obstructed labor among mothers who gave birth in Ethiopia.

\section{Methods}

This systematic review and meta-analysis were conducted to estimate incidence, causes, and maternofetal outcomes of obstructed labor among mothers who gave birth in Ethiopia. We used the Preferred Reporting Items for Systematic Reviews and Meta-Analyses (PRISMA) checklist guideline [23] (Additional file 1).

\section{Searching strategy}

First, the PROSPERO database and database of abstracts of reviews of effects (DARE) (http://www.library.UCSF. edu) were searched to check whether published or ongoing projects exist related to the topic. The literature search strategy, selection of studies, data extraction, and result reporting were done in accordance with the Preferred Reporting Items for Systematic Reviews and Meta-Analyses (PRISMA) guidelines [24]. We searched PubMed, Google Scholar, EMBASE, Cochrane Library, HINARI, AFRO Library Databases, and African Online Journal databases for all available studies using the following terms: "obstructed labor", "prolonged labor", "obstetric complications", "childbirth", "labor abnormalities", "factors", and "Ethiopia". The search string was developed using "AND" and "OR" Boolean operators. Searching terms were based on adapted PICO principles to search through the above-listed databases to access all relevant articles. For unpublished studies, the official website of Ethiopian's University research repository online library (University of Gondar and Addis Ababa University) were used. The searching period was from September $1 / 2020$ to November 30/2020.

\section{Inclusion and exclusion criteria}

All observational studies reporting the incidence of obstructed labor and/or associated factors in Ethiopia were included in this review. Both unpublished and published research articles, conducted in English language were included. Whereas duplicated studies, case reports, qualitative studies, anonymous reports, articles without full text, and abstract and editorial reports were excluded from the study.

\section{Operational definition}

Obstructed Labor: also known as labor dystocia, is a failure to progress due to mechanical problems-a 
mismatch between fetal size, or more accurately, the size of the presenting part of the fetus, and the mother's pelvis, although some malpresentation, notably a brow presentation or a shoulder presentation. it is diagnosed when the duration of labor $>24 \mathrm{~h}$, a laboring mother became unable to support herself or unable to move her lower extremities, with deranged vital signs, distended bladder, Bandle's ring formed in the lower uterine segment, fetal distress or death, edematous vulva, big caput, significant molding, foul-smelling and thick meconium-stained amniotic fluid [3, 25].

\section{Causes of obstructed labor}

The commonest cause of obstructed labor is craniopelvic disproportion (CPD). This could arise as a result of reduced pelvic dimension from childhood, maternal malnutrition, infection, poliomyelitis, deformity, sickle cell disease, or in teenagers increased diameter of the presenting part, such as malposition and malpresention. These include brow presentation, compound presentation, occipto-posterior, and mento-posterior in face presentation and congenital malformation (hydrocephalus, fetal ascites, and double monsters) [26, 27].

\section{Complications of obstructed labor}

Apart from maternal death, obstructed labor had different maternal outcomes such as uterine rupture, postpartum hemorrhage, puerperal sepsis, Vesico-Vaginal fistula (VVF), recto-vaginal fistula (RVF), and fetal outcomes including birth asphyxia, stillbirth, neonatal jaundice, and umbilical sepsis. Women who experience obstructed labor for a prolonged time can be complicated with fistulas. Besides their physical wounds, serious social issues of divorce, separation from religious exercises, detachment from their families which can worsen poverty, and malnutrition are the major problems of obstructed labor [3, 19, 20].

\section{Cephalopelvic disproportion (CPD)}

Is an inadequate size of the maternal pelvis, compared to the fetal head, which prevents the fetus from passing through the pelvic cavity during delivery, and causes obstructed labor [28].

\section{Quality assessment}

After collecting the findings from all databases, the articles were exported to Microsoft Excel spreadsheet. The methodological quality of each study (sampling strategy, response rate, and representativeness of the study), comparability, and outcome were checked using the NOS tool. Newcastle-Ottawa Quality Assessment Scale (NOS) for cross-sectional, and case-control studies was used to assess the methodological quality of a study, and to determine the extent to which a study has addressed the possibility of bias in its design, conduct, and analysis [29]. All included articles scored (NOS) 7 and more can be considered as "good" studies with low risk (Additional file 2).

\section{Data extraction}

Microsoft Excel (2016), and Stata version 11.0 (Stata Corporation, College Station, Texas, USA) software were used for data entry and analysis, respectively. The data was extracted by using a standardized Joanna Briggs Institute (JBI) data extraction format. During data extraction; the name of the author, sample size, publication year, study design, prevalence, response rate, population outcome, study site, and different contributing factors were included. Moreover, the incidence, and outcomes of obstructed labor with 95\% CI and associated factors were collected [30].

\section{Statistical analysis}

As the test statistic showed significant heterogeneity among studies $\left(\mathrm{I}^{2}=98.0 \%, p<0.05\right)$ the Random-effects model was used to estimate the DerSimonian and Laird's pooled effect [31]. Cochran's Q chi-square statistics and $\mathrm{I}^{2}$ statistical test was conducted to assess the random variations between primary studies [32]. In this study, the heterogeneity of included studies was interpreted as an $\mathrm{I}^{2}$ value of $25 \%=$ low, $50 \%=$ moderate, and $75 \%=$ high [33]. In case of high heterogeneity, subgroup analysis and sensitivity analyses were run to identify possible moderators of this heterogeneity. Potential publication bias was assessed by visually inspecting funnel plots and objectively using the Egger's test (i.e. $p<0.05$ ) [34]. To account for any publication bias, we used the trim-and-fill method, based on the assumption that the effect sizes of all studies are normally distributed around the center of a funnel plot. The meta-analysis was performed using the Stata version 11.0 (Stata Corporation, College Station, Texas, USA) software. Finally, for all analyses, $P<0.05$ was considered statistically significant.

\section{Results}

\section{Study selection and data extraction}

The search strategy identified 80 articles from PubMed, 60 articles from Google Scholar, 45 articles from Cochrane Library, 10 articles from African Journals Online, 7 articles from Ethiopian's University online library, and 2 articles from manual search. Of which, 134 were excluded due to duplication, 35 through review of titles and abstracts. Additionally, 44 full-text articles were excluded for not reporting the outcome variable and other reasons. Finally, 16 articles were 
included to analyze the incidence, outcome, and associated factors of obstructed labor (Fig. 1).

\section{Study characteristics}

In this review, 16 relevant studies were included with a sample size of 28,951. Among sixteen studies thirteen were cross sectional $[1,14,35-45]$ and three case-controls [46-48] in study design. Regarding the geographical area, six from Oromia [14, 35, 36, 40, 41, 47], four [3, 37, 39, 42] from Southern Nation Nationalities and People (SNNPR), and four [1, 38, 43, 48] from Tigray region, two studies $[45,46]$ were from Amhara region. Among the included studies the largest sample size was 13,425 [41], whereas the smallest was 90 [48] (Table 1).

\section{Incidence of obstructed labor in Ethiopia}

Primarily, all three case-control [46-48] studies were not considered in the incidence estimation, because they did not report the incidence of obstructed labor, but all studies were included in factor analysis. The pooled incidence of obstructed labor is presented on a forest plot (Fig. 2). Therefore, the estimated incidence of obstructed labor among mothers who gave birth in Ethiopia was $12.93 \%$ (95\% CI: $10.44-15.42, \mathrm{I}^{2}=98.0 \%, p<0.001$ ).

\section{Publication bias}

The funnel plot was assessed for asymmetry distribution of the prevalence of obstructed labor among mothers who gave birth in Ethiopia (Fig. 3). Egger's regression test showed a p-value of 0.259 with no evidence of publication bias.

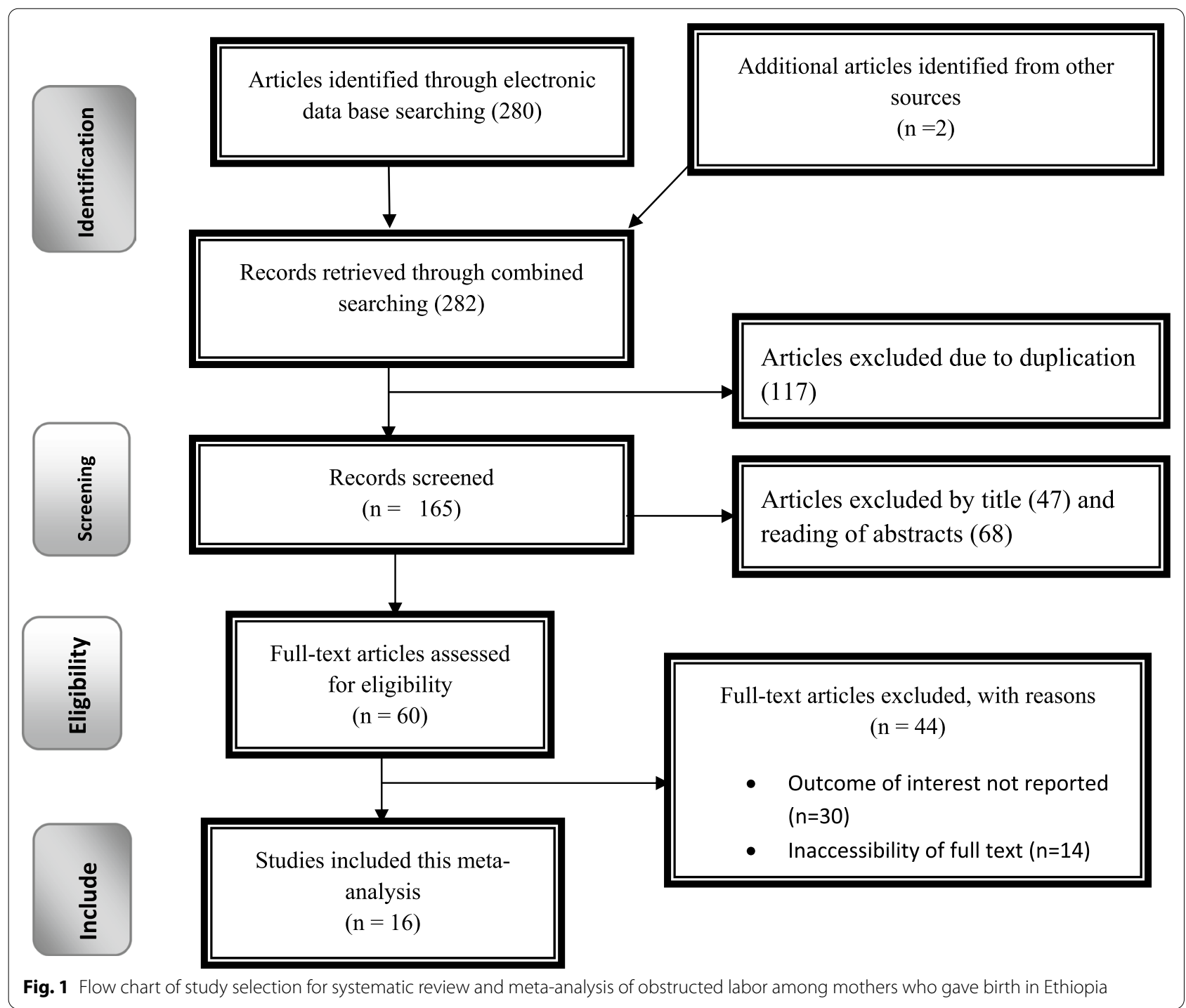


Table 1 Descriptive summary of nineteen included studies in the systematic review and meta-analysis

\begin{tabular}{|c|c|c|c|c|c|}
\hline Authors & Sample size & Prevalence (\%) & Study region & Study design & complications of obstructed labor \\
\hline Shimelis et al. [35] & 1468 & 12.2 & Oromia & Cross sectional & Uterine rupture, sepsis, and low first minute APGAR score \\
\hline Andualem et al. [37] & 1825 & 7.95 & SNNPR & Cross sectional & postpartum hemorrhage, uterine rupture, and perinatal mortality \\
\hline Amanuel et al. [21] & 5980 & 3.3 & Tigray & Cross sectional & $\begin{array}{l}\text { Caesarean section, craniotomy, instrumental delivery, hysterec- } \\
\text { tomy, ruptured uterus, Maternal mortality }\end{array}$ \\
\hline Ashebir et al. [41] & 13,425 & 7 & Oromia & Cross sectional & Ruptured uterus, stillbirth, maternal mortality, and perinatal death \\
\hline Mulugeta et al. [46] & 801 & N/A & Amhara & Case control & Cesarean section, infertility, and uterine rupture \\
\hline Tizita et al. [22] & 385 & 34.3 & Oromia & Cross sectional & Maternal death, uterine rupture, hysterectomy, and anemia \\
\hline Sisay et al. [39] & 327 & 15.6 & SNNPR & Cross sectional & $\begin{array}{l}\text { Ruptured uterus, cesarean section, wound infection, and neona- } \\
\text { tal death }\end{array}$ \\
\hline Yemane et al. [38] & 1231 & 14.7 & Tigray & Case control & Stillbirth, perinatal mortality, and neonatal mortality \\
\hline Tewodros et al. [48] & 90 & N/A & Tigray & Cross sectional & $\begin{array}{l}\text { Sepsis, postpartum hemorrhage, Vesico Vaginal Fistula, anemia, } \\
\text { stillbirth, birth asphyxia, and birth injury }\end{array}$ \\
\hline Daniel et al. [14] & 321 & 18.1 & Oromia & Cross sectional & $\begin{array}{l}\text { postpartum hemorrhage, ruptured uterus, puerperal sepsis, and } \\
\text { maternal death }\end{array}$ \\
\hline Ritbano et al. [42] & 344 & 18.6 & SNNPR & Case control & Maternal death, anemia, and infection \\
\hline Johannes et al. [47] & 143 & N/A & Oromia & Cross sectional & $\begin{array}{l}\text { sepsis, hemorrhage that required transfusion of several units of } \\
\text { blood, ruptured uterus, respiratory tract infection with cardiac } \\
\text { failure), low APGAR score, and immediate newborn death }\end{array}$ \\
\hline Asnakech et al. [36] & 384 & 9.6 & Oromia & Cross sectional & N/A \\
\hline Gebresilasea et al. [43] & 616 & 6.7 & Tigray & Cross sectional & $\begin{array}{l}\text { stillbirths or had died immediately after delivery, Postpartum } \\
\text { hemorrhaged, puerperal sepsis, uterine rupture, hysterectomy, } \\
\text { and cesarean section }\end{array}$ \\
\hline Wayu et al. [44] & 844 & 16.8 & SNNPR & Cross sectional & $\begin{array}{l}\text { Intrapartal fetal and early neonatal deaths, instrumental delivery, } \\
\text { and meconium stained amniotic fluid }\end{array}$ \\
\hline Oumar et al. [45] & 407 & 10.7 & Amhara & Cross sectional & Maternal death, anemia, stillbirth, and hysteretomy \\
\hline
\end{tabular}

\section{Sensitivity analysis}

This systematic review and meta-analysis showed that the point estimate of its omitted analysis lies within the confidence interval of the combined analysis. Therefore, trim and fill analysis was no further computed (Fig. 4).

\section{Subgroup analysis}

Subgroup analysis was employed with the evidence of heterogeneity. In this study, the Cochrane $\mathrm{I}^{2}$ statistic was 98.0\%, $P<0.001$, shower the presence of marked heterogeneity. Therefore, subgroup analysis was done using the study region and sample size. As a result, obstructed labor was high in Southeastern Ethiopia 15.14\% (95\% CI: 11.61-18.66), regarding sample size, the highest incidence was in the study with the sample size less than 1000 [16.93\% (95\% CI: 10.92-21.14)] (Figs. 5 and 6).

\section{Risk factors for the incidence of obstructed labor}

The association between not having antenatal care follow-up, rural residency, referred from health centers and visited hospitals after at least $12 \mathrm{~h}$ of labor with obstructed labor was carried out.

A total of six articles were included to identify the association between referred from health centers and visited hospitals after at least $12 \mathrm{~h}$ of labor and obstructed labor. Mother's referred from health centers, and visited hospitals after at least $12 \mathrm{~h}$ of labor develop obstructed labor by $58.52 \%$ than mothers who visited hospitals in short hours of labor (58.52\%, 95\% CI: 35.73-82.31).

A total of five articles were included to identify the association between rural residency and obstructed labor. Mother's residency (as defined as rural and urban) was significantly associated with obstructed labor. Mother's from rural areas were more likely to have obstructed labor than those (women) from urban areas, $77.86 \%$ (95\% CI: 63.07-92.66).

Moreover, four studies showed a significant association between not having antenatal care follow-up and obstructed labor. Mother's who did not have antenatal care follow-up were $67.3 \%$ more likely to develop obstructed labor (67.3\%, 95\% CI: 33.32-101.28) compared to mothers who had antenatal care follow-up (Table 2).

Additionally, the two major causes of obstructed labor were cephalo-pelvic disproportion $64.65 \%$ (95\% CI: 57.15-72.14), and malpresentation and malposition in 27.24\% (95\% CI: 22.05-32.42) of the cases (Figs. 7 and 8).

Materno-fetal complications following obstructed labor in Ethiopia. 


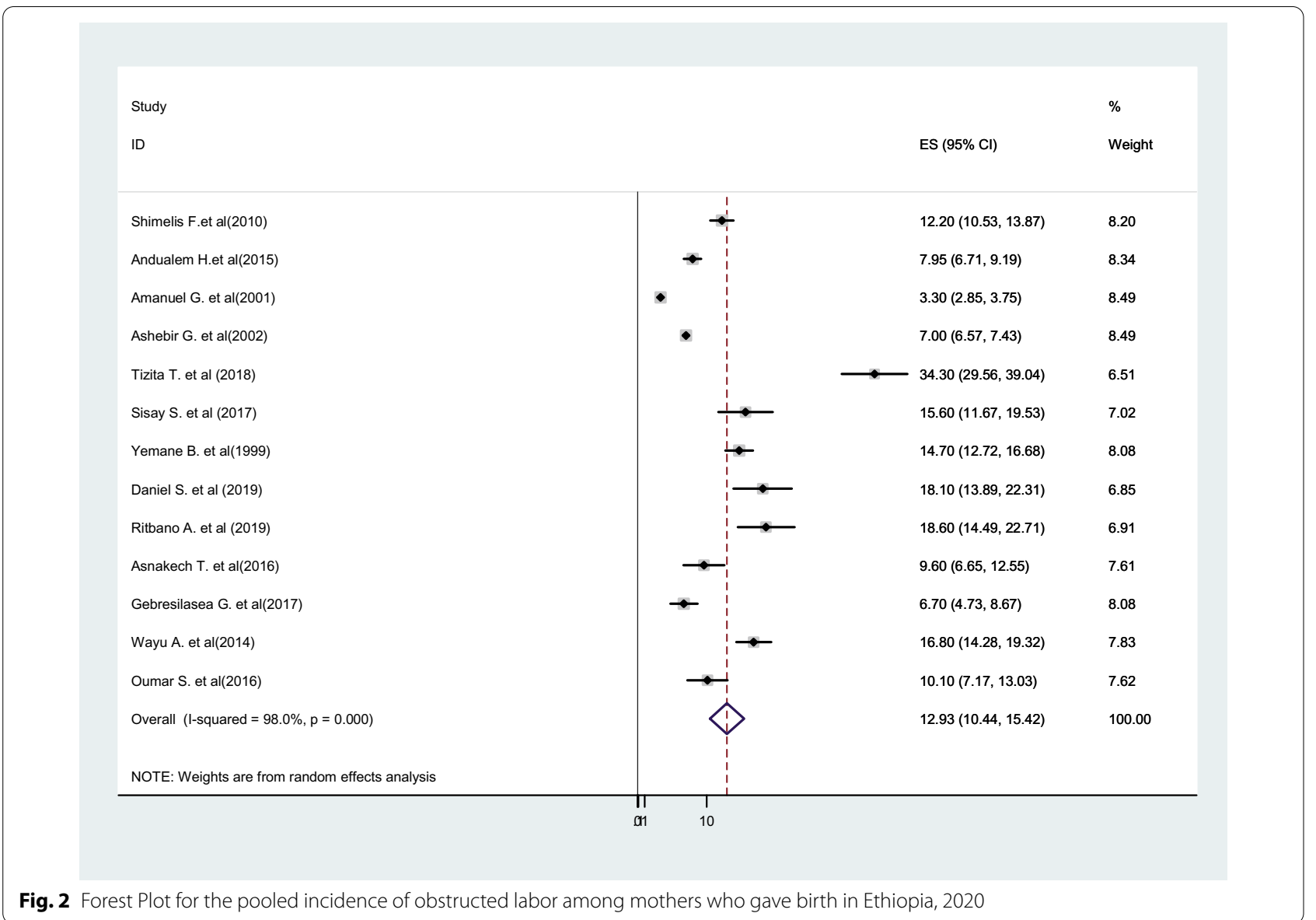

Following obstructed labor, different adverse maternal and neonatal complications were reported. Sepsis, stillbirth, postpartum hemorrhage, uterine rupture, and maternal death were the most common complications following obstructed labor (Table 3).

\section{Discussion}

Obstructed labor is a life-threatening obstetrical complication associated with significant maternal as well as fetal morbidity and mortality. Early recognition and immediate intervention are important to prevent associated complications and to improve maternal and fetal outcomes [21]. Several interventions, such as the utilization of the partograph to monitor labor and provision of emergency obstetrical care services have been proposed to reduce the incidence of obstructed labor, and its squeal. However, the prevalence remains high in the developing countries [49].

The purpose of this review was to assess the incidence, mernofetal outcome, and associated factors of obstructed labor by reviewing the findings of available primary studies. The pooled incidence of obstructed labor in Ethiopia was $12.93 \%$. The result higher than the studies conducted in India [50] 1.9\%, Pakistan [51] 2.1\%, Nigeria [52] 4.7\%, and Uganda $10.5 \%$ [53]. The possible reason might be poor ANC follow up, high homebirth prevalence, teenage pregnancy, low socioeconomic status, poor infrastructure, and poor referral system in Ethiopia [54-56].

This study also elucidated that, $67 \%$ of the obstructed labor cases did not have ANC follow-up during pregnancy. The result is supported by studies conducted in Pakistan [57], and Nigeria [20]. This might be the fact that not having antenatal care during pregnancy may decrease women knowledge about their pregnancy condition like multiple pregnancies, big baby, fetal anomalies, and other risk factors for obstructed labor. Moreover, women who don't have antenatal care are prone to home childbirth, poor awareness about birth preparedness and complication readiness plan, and danger signs of pregnancy which in turn increase the risk of obstructed labor.

Among mothers who had obstructed labor, $77.86 \%$ were from rural areas. The result is in line with studies conducted in Uganda [53] and Bangladesh [57]. This could be due to women residing in rural areas, health facilities are distant, and accesses to information about institutional deliveries are limited. This might result in a 


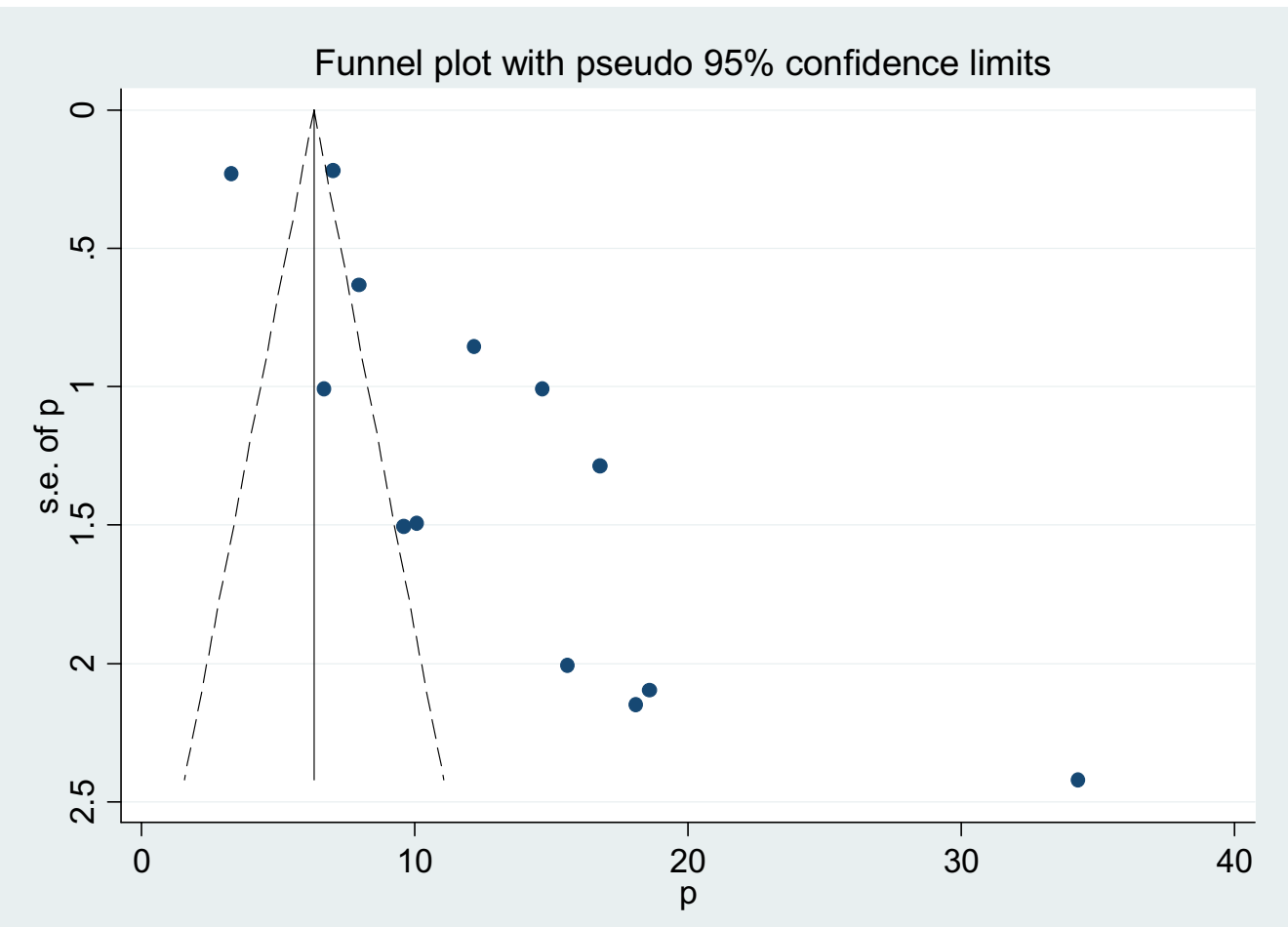

Fig. 3 Funnel plot with 95\% confidence limits of the pooled incidence of obstructed labor among mothers who gave birth in Ethiopia, 2020

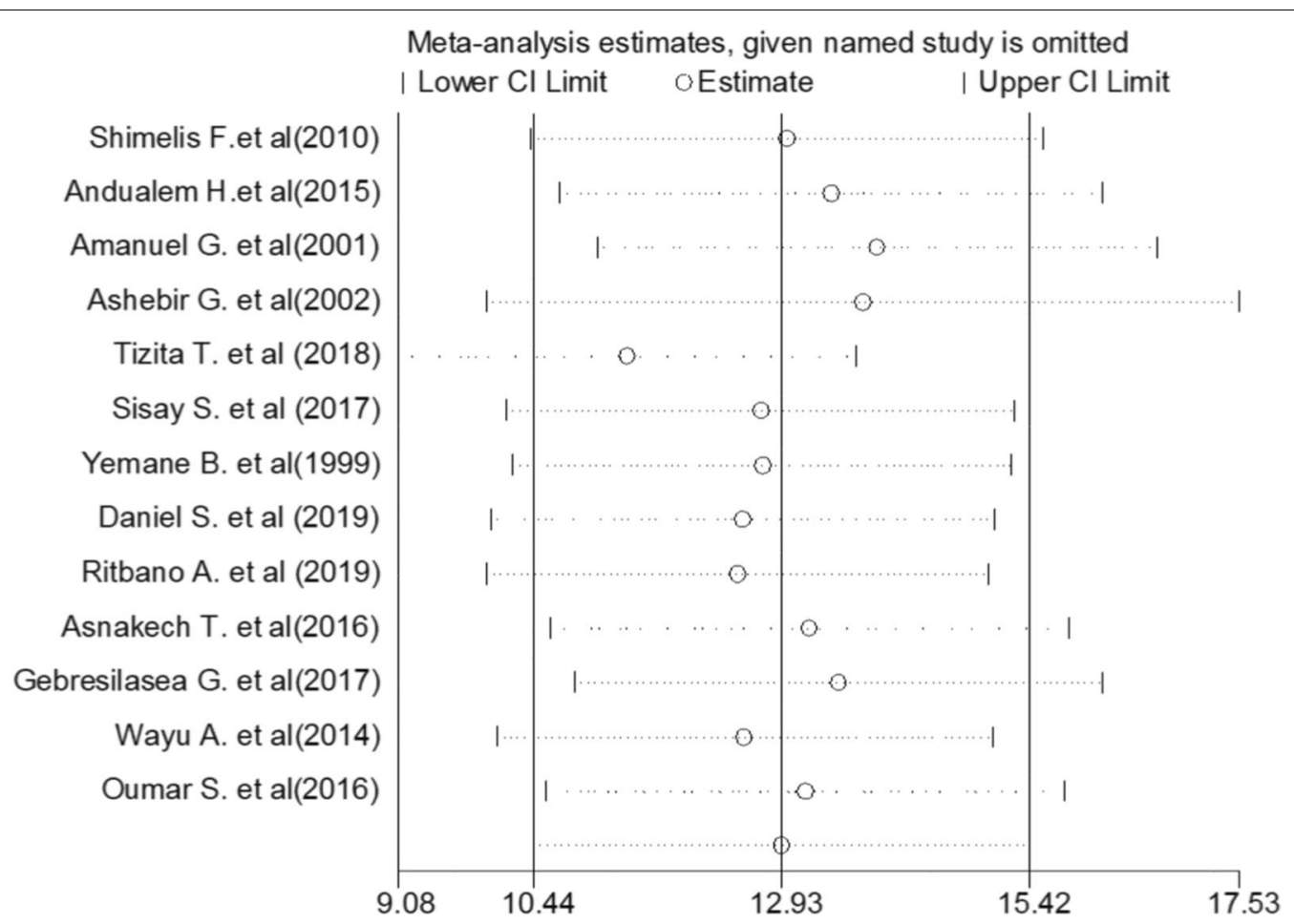

Fig. 4 Sensitivity analysis of the pooled incidence of obstructed labor among mothers who gave birth in Ethiopia, 2020 


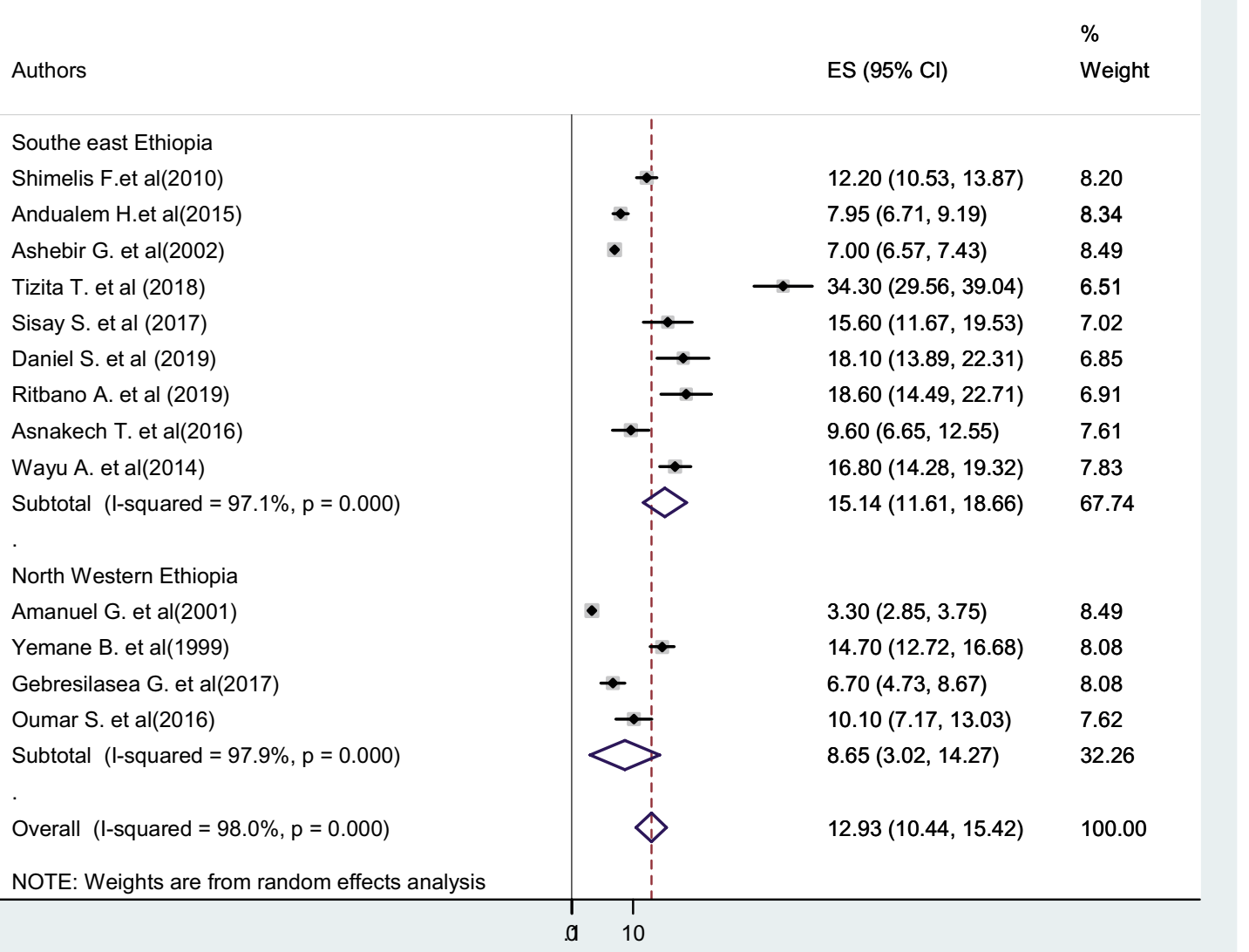

Fig. 5 Subgroup analysis of the pooled incidence of obstructed labor among mothers who gave birth in Ethiopia based on the study region, Southeastern Ethiopia

delay to decide for seeking health care as early as possible and delay in reaching a health facility which contributes a lot to the occurrence of obstructed labor.

Additionally, 58.52\% of mothers who had obstructed labor were referred from health centers and visited hospitals after at least $12 \mathrm{~h}$ of labor. The result is supported by studies conducted In Ghana [58] and Eastern Uganda [59]. This could be explained as women might be referred after a long time of stay at the lower level facilities either due to lack of transportation, lack of infrastructure, poor decision of health care providers, and refusal of families which promote the occurrence of obstructed labor.

The main obstetric causes of obstructed labor in this review were cephalopelvic disproportion accounted for $64.65 \%$. The result is supported by studies in Uganda [53], Nigeria [5], and India [50]. This could be explained as the prevalence of CPD is high in Ethiopia, where girls are small in stature, grow up malnourished, marry at a young age, and become pregnant before their pelvis is fully grown [60]. Additionally, a cross-sectional study of obstetric fistula patients in Ethiopia revealed that the mean ages at the first marriage and at the delivery that caused the fistula were 14.7 and 17.8 years respectively [61]. Indeed, $13 \%$ of the girls surveyed in the study in 2016 between 15 and 19 years of age had begun childbearing, including $1.6 \%$ of 15 year-olds, $4.4 \%$ of 16-year-olds and $13 \%$ of 17 year-olds [62]. Malposition and malpresentation were also responsible for $27.4 \%$ of obstructed labor, which was consistent with a study conducted at Pakistan Public Sector University [63].

Sepsis was the commonest maternal complication of obstructed labor accounted for $38.08 \%$ of cases. The result is in line with studies conducted in Uganda [53], India [50], Eastern Nigeria [52], and the United States 


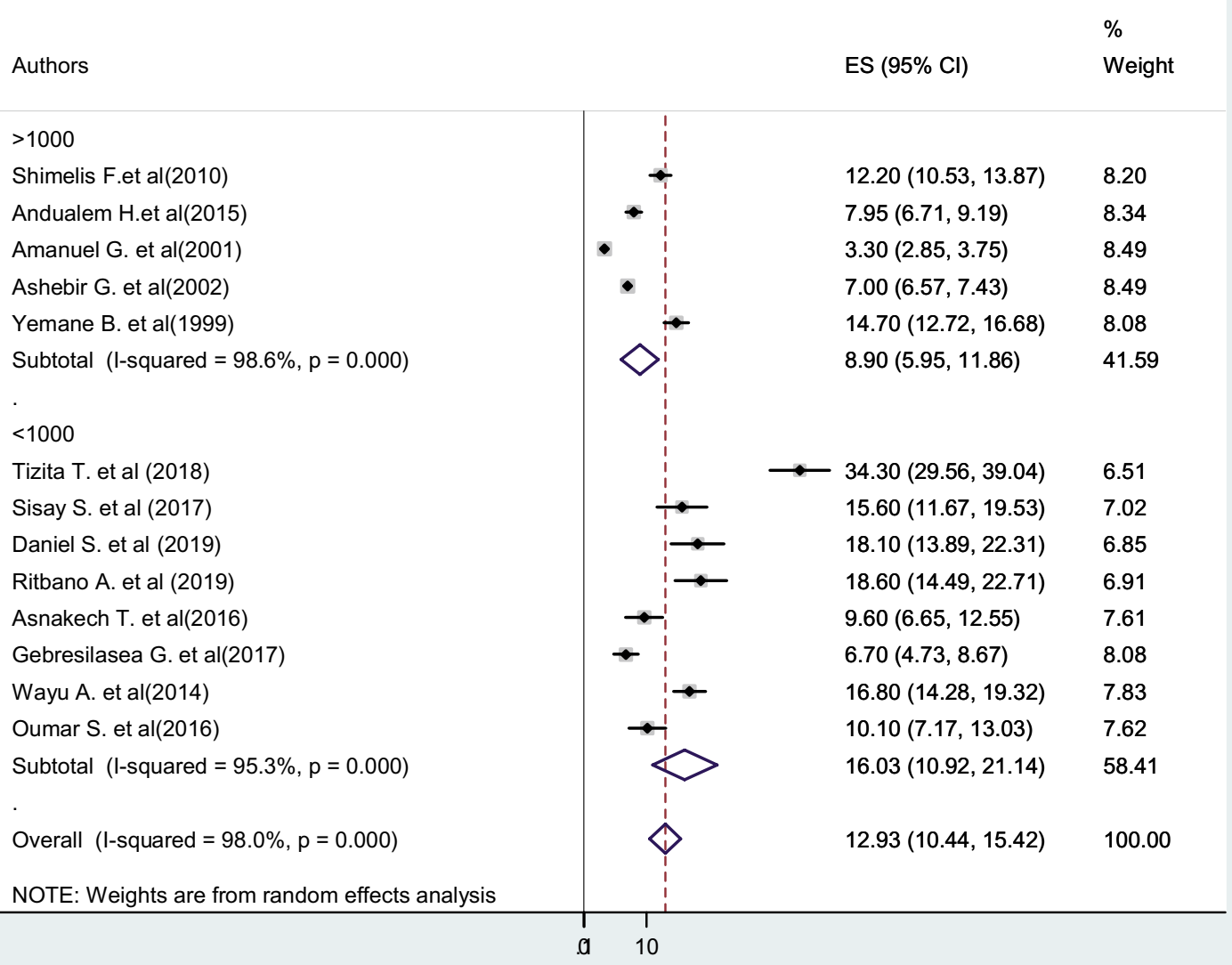

Fig. 6 Subgroup analysis of the pooled incidence of obstructed labor among mothers who gave birth in Ethiopia based on sample size

Table 2 Factors for the incidence of obstructed labor in Ethiopia

\begin{tabular}{llllrrr}
\hline Factors for obstructed labor & $\begin{array}{l}\text { Number of } \\
\text { studies }\end{array}$ & Model & $\begin{array}{l}\text { Status of } \\
\text { heterogeneity }\end{array}$ & Prevalence (95\% Cl) & $P^{2}$ (\%) & $P$-value \\
\hline Rural residency & 5 & Random & Marked & $77.86 \%$ (95\% Cl: 63.07-92.66) & 99.6 & $\leq 0.001$ \\
Not having ANC & 4 & Random & Marked & $67.3 \%$ (95\% Cl: 33.32-101.28) & 99.8 & $\leq 0.001$ \\
$\begin{array}{l}\text { Referred from health center after } \\
12 \text { h duration of labor }\end{array}$ & 6 & Random & Marked & $58.52 \%$ (95\% Cl: 35.73- 82.31) & 98.1 & $\leq 0.001$ \\
\hline
\end{tabular}

[64]. Additionally, postpartum hemorrhage resulted in $33.54 \%$ of obstructed cases. The result is supported by studies in Norway [65] and Le Ray et al. [66].

Uterine rupture resulted in $29.84 \%$ of obstructed cases. The result is supported by the study conducted in Uganda [67], Dar es Salaam, and the USA [68]. The reason for this could be during obstructed labor there is an impossible barrier (obstruction) preventing its descent despite strong uterine contractions, which increases the risk of uterine rupture.
This review revealed that obstructed labor results stillbirth $38.59 \%$ of cases. The result is in line with studies in Boston, Massachusetts, United States [64], and Pakistan [51]. The possible reason might be obstructed labor is when the baby does not exit the pelvis during childbirth due to being physically blocked, despite the uterus contracting, resulted in the baby not getting enough oxygen which may result in death. Moreover, as labor is obstructed, the fetal head impacts on the soft tissue of the pelvic floor, pinning 


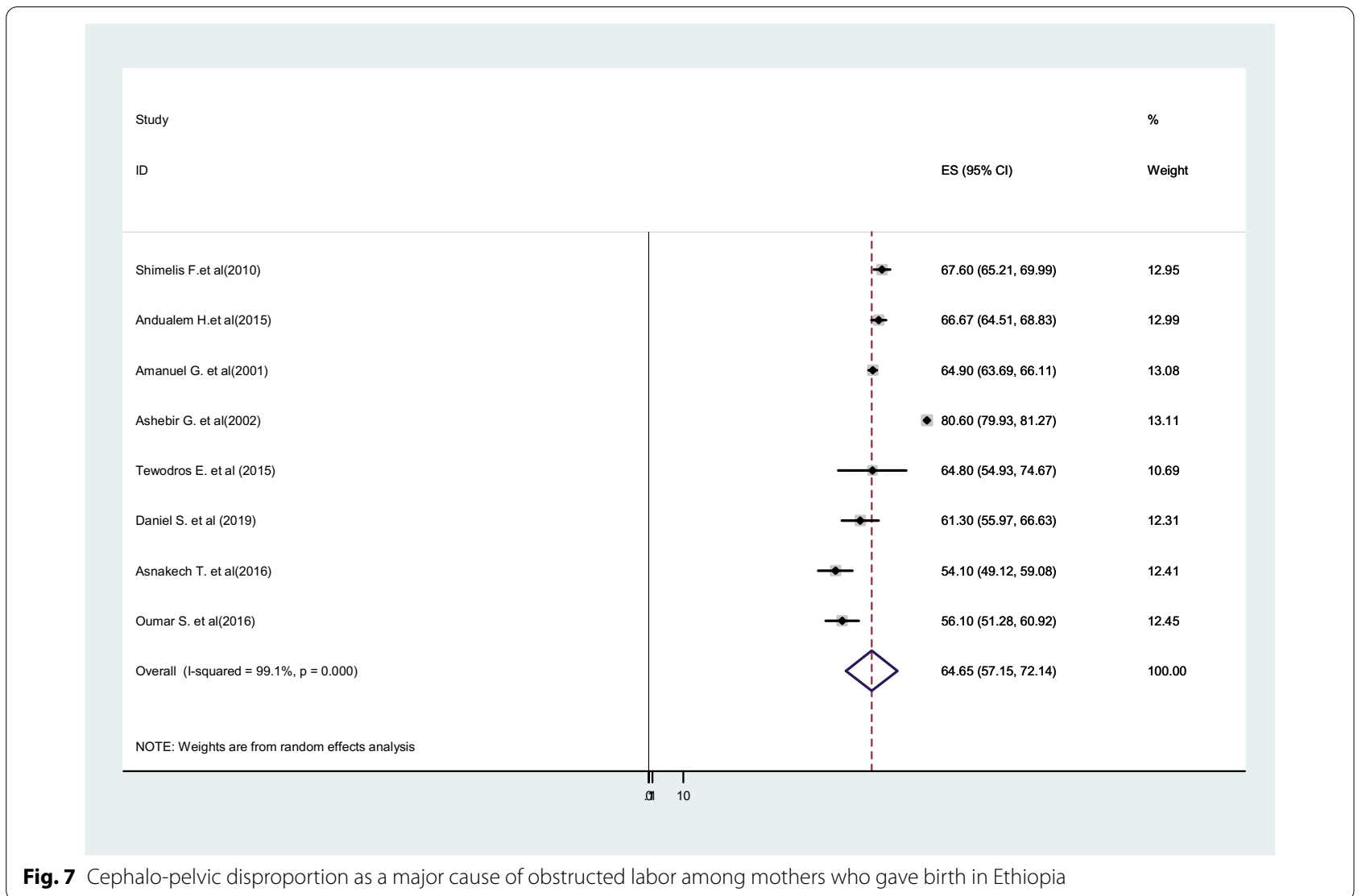

the bladder base and the urethra against the pelvic bone. In the absence of any intervention, this condition may last for several days; the fetus may die and the results stillbirth.

Maternal death has also resulted in $17.27 \%$ obstructed labor cases in Ethiopia. The result is supported by a systematic review in Sub-Saharan Africa [69], Uganda [53], and Eastern Nigeria [52]. This shocking figure is certainly an underestimation of the problems, because deaths due to obstructed labor are often classified under other complications (such as sepsis, postpartum hemorrhage or ruptured uterus). This could be explained by obstructed labor results, dehydration, exhaustion, fistula, uterine rupture, sepsis, postpartum hemorrhage, anemia, and shock which all could result in maternal death.

\section{Limitation}

Since it is the first systematic review and meta-analysis, it is taken as a strength. The included articles were restricted to the English language only; this is a limitation of the study as it missed studies published in local languages. Additionally, one of the limitations of this systematic review is the credibility of the unpublished and non-peer-reviewed publications included in this review.

\section{Conclusion}

This study revealed the high incidence of obstructed labor and its complications in Ethiopia. Not having antenatal care follow-up, rural residency, and referred from health centers and visited hospitals after at least $12 \mathrm{~h}$ of labor were contributing factors for the incidence of obstructed labor. Additionally, the major causes of obstructed labor were cephalo-pelvic disproportion and malpresentation and malposition. Sepsis, stillbirth, postpartum hemorrhage, uterine rupture, and maternal death were the commonest complications of obstructed labor among mothers who gave birth in Ethiopia. Therefore, to prevent the incidence of obstructed labor; promoting ANC service utilization during pregnancy, improving the referral system, and infrastructure to reach health faculty that had a capacity to manage obstructed labor is recommended. Moreover, it is better to promote institutional service utilization for the prevention and early management of obstructed labor and its complications. 


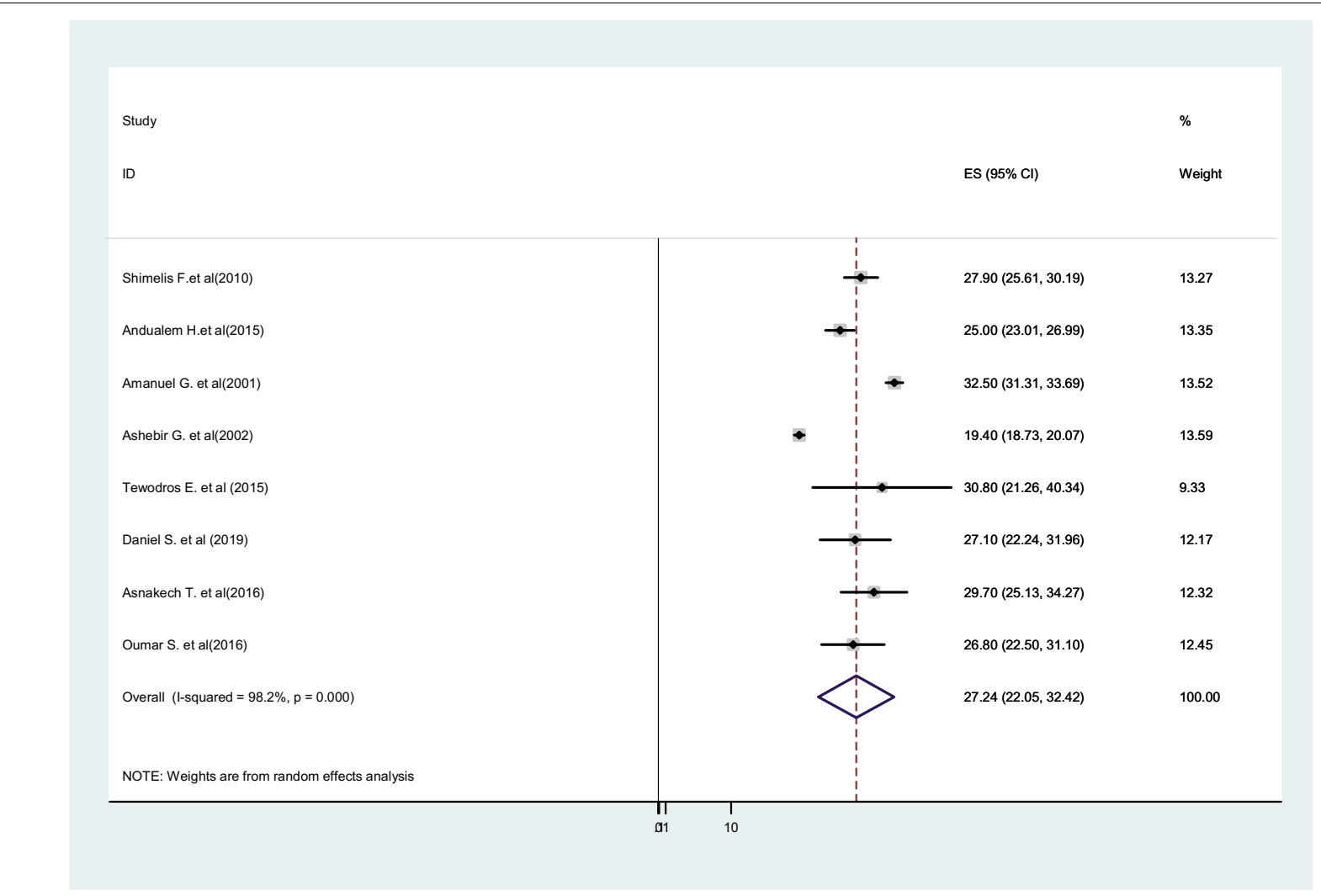

Fig. 8 Malpresentation and malposition as a major cause of obstructed labor among mothers who gave birth in Ethiopia

Table 3 Materno-fetal complications following obstructed labor in Ethiopia

\begin{tabular}{|c|c|c|c|c|c|c|}
\hline Complication s of obstructed labor & $\begin{array}{l}\text { Number of } \\
\text { included studies }\end{array}$ & Model & $\begin{array}{l}\text { Status of } \\
\text { heterogeneity }\end{array}$ & Prevalence $(95 \% \mathrm{Cl})$ & $1^{2}(\%)$ & $P$-value \\
\hline Sepsis & 5 & Random & Marked & $38.08 \%(95 \%$ Cl: $29.55-46.61)$ & 97.5 & $\leq 0.001$ \\
\hline Stillbirth & 8 & Random & Marked & $38.59 \%$ (95\% Cl: 25.49- 51.68) & 99.8 & $\leq 0.001$ \\
\hline Postpartum hemorrhage & 5 & Random & Marked & $33.54 \%$ (95\% Cl: 12.06- 55.02) & 99.2 & $\leq 0.001$ \\
\hline Uterine rupture & 10 & Random & Marked & $29.84 \%$ (95\% Cl: 21.09-38.58) & 98.7 & $\leq 0.001$ \\
\hline Maternal death & 6 & Random & Marked & $17.27 \%(95 \%$ Cl: $13.47-48.02)$ & 97.2 & $\leq 0.001$ \\
\hline
\end{tabular}

\section{Abbreviations}

AA: Addis Ababa; Cl: Confidence Interval; CPD: Cepalo-Pelvic Disproportion; AOR: Adjusted Odds Ratio; PRISMA: Preferred Reporting Items for Systematic Reviews and Meta-Analyses; SNNPR: Southern Nation Nationality and Peoples Representative.

\section{Supplementary Information}

The online version contains supplementary material available at https://doi. org/10.1186/s12978-021-01103-0.

Additional file 1. Prisma checklist.

Additional file 2. NOS quality assessment score for the included studies.

\section{Acknowledgements}

Not applicable

Authors' contributions

The author (AAA) conducted the data analysis and the author read and approved the final manuscript.

\section{Funding}

No funding was obtained for this study.

\section{Availability of data and materials}

The data sets generated during the current study are available from the corresponding author on reasonable request. 


\section{Declarations}

Ethics approval and consent to participate

Not applicable.

\section{Consent for publication}

Not applicable.

\section{Competing interests}

The author declare that I have no competing interests.

Received: 17 November 2020 Accepted: 9 February 2021

Published online: 10 March 2021

\section{References}

1. Gessessew A, Mesfin M. Obstructed labour in Adigrat Zonal hospital, Tigray Region, Ethiopia. Ethiop J Health Dev. 2003;17(3):175-80.

2. Kabakyenga JK, Östergren P-O, Turyakira E, Mukasa PK, Pettersson KO Individual and health facility factors and the risk for obstructed labour and its adverse outcomes in south-western Uganda. BMC Pregnancy Childbirth. 2011;11(1):73.

3. Abraham W, Berhan Y. Predictors of labor abnormalities in university hospital: unmatched case control study. BMC Pregnancy Childbirth. 2014;14(1):256.

4. Gabbe SG, Niebyl JR, Simpson JL, Landon MB, Galan HL, Jauniaux ER, Driscoll DA, Berghella V, Grobman WA. Obstetrics: normal and problem pregnancies e-book. Elsevier Health Sciences. 7th ed. 2016. eBook ISBN: 9780323392181.

5. Nwogu-Ikojo EE, Nweze SO, Ezegwui HU. Obstructed labour in Enugu, Nigeria. J Obstet Gynaecol. 2008;28(6):596-9.

6. Nkwo PO, Lawani LO, Ubesie AC, Onodugo VA, Obu HA, Chinawa JM. Poor availability of skilled birth attendants in Nigeria: a case study of enugu state primary health care system. Ann Med Health Sci Res. 2015;5(1):20-5.

7. Melah GS, El-Nafaty AU, Massa AA, Audu BM. Obstructed labour: a public health problem in Gombe, Gombe State, Nigeria. J Obstet Gynaecol. 2003;23(4):369-73.

8. Onwuhafua PI. Dying undelivered. J Obstet Gynaecol. 2002;22(2):155-8.

9. Cetin O, Yolli H, Cim N, Yıldızhan R, Sahin HG. A fatal and extremely rare obstetric complication: neglected shoulder presentation at term pregnancy. Case Rep Obstet Gynecol. 2015;2015:819874.

10. Amo-Mensah S, Elkins TE, Ghosh TS, Greenway F, Waite V. Obstetric destructive procedures. Int J Gynaecol Obstet. 1996:54(2):167-8.

11. Gogoi MP. Maternal mortality from Caesarean section in infected cases. J Obstet Gynaecol Br Commonw. 1971;78(4):373-6.

12. Gupta U, Chitra R. Destructive operations still have a place in developing countries. Int J Gynaecol Obstet. 1994;44(1):15-9.

13. Liu L, Oza S, Hogan D, Chu Y, Perin J, Zhu J, et al. Global, regional, and national causes of under-5 mortality in 2000-15: an updated systematic analysis with implications for the Sustainable Development Goals. Lancet. 2016;388(10063):3027-35

14. Shiferaw D, Toma S. Prevalence and associated factors of obstructed labour, and its outcome among mothers delivered at Gimbi Public Hospital, Wollega Western Ethiopia. EC Gynaecol. 2019;8:282-93.

15. Abebe B, Busza J, Hadush A, et al. 'We identify, discuss, act and promise to prevent similar deaths': a qualitative study of Ethiopia's maternal death surveillance and response system. BMJ Global Health. 2017;2:e000199.

16. Fantu S, Segni H, Alemseged F. Incidence, causes and outcome of obstructed labor in jimma university specialized hospital. Ethiop J Health Sci. 2010;20(3):145-51.

17. Kuruvilla S, Bustreo F, Kuo T, Mishra CK, Taylor K, Fogstad H, et al. The Global strategy for women's, children's and adolescents' health (20162030): a roadmap based on evidence and country experience. Bull World Health Organ. 2016;94(5):398-400.

18. World Health Organization. World malaria report 2015. Geneva: World Health Organization; 2016.

19. MacKeith N, Wur WB. The baby has not come: obstructed labour. South Sudan Med J . 2013;6(1):7-9.
20. Khooharo Y, Majeed T, Khawaja MA, Majeed N, Majeed N, Malik MN, et al. Even in 21st century still obstructed labor remains life threatening condition. Ann King Edw Med Univ. 2012;18(3):279.

21. Gessessew A, Mesfin M. Obstructed labour in Adigrat Zonal Hospital, Tigray Region. Ethiopia Ethiop J Health Dev. 2002;17:175-80.

22. Wube TT, Demissie BW, Assen ZM, Gelaw KA, Fite RO. Magnitude of obstructed labor and associated factors among women who delivered at public hospitals of Western Harerghe Zone, Oromia. Ethiopia. Clin Med Res. 2018;7(6):135-42. https://doi.org/10.11648/j.cmr.20180706.11.

23. Moher D, Liberati A, Tetzlaff J, Altman D. Preferred reporting items for systematic reviews and meta-analyses: The PRISMA Statement. PLoS Med. 2009;6(6):el000097.

24. Moher D, Liberati A, Tetzlaff J, Altman DG. Preferred reporting items for systematic reviews and meta-analyses: the PRISMA statement. PLoS Med. 2009;6(7):e1000097

25. Neilson J, Lavender T, Quenby S, Wray S. Obstructed labour: Reducing maternal death and disability during pregnancy. Br Med Bull. 2003:67(1):191-204

26. World Health Organization. World Health Organization Education material for teachers of midwifery managing of prolonged and obstructed labor. Geneva: World Health Organization; 2008.

27. Dutta DC, Konar H. Text book of obstetrics: including perinatology and contraception. Calcutta, India: New Central Book Agency Ltd; 2006.

28. Tolentino L, Yigeremu M, Teklu S, Attia S, Weiler M, Frank N, et al. Threedimensional camera anthropometry to assess risk of cephalopelvic disproportion-related obstructed labour in Ethiopia. Interface Focus. 2019;9(5):20190036.

29. Downes MJ, Brennan ML, Williams HC, Dean RS. Development of a critical appraisal tool to assess the quality of cross-sectional studies (AXIS). BMJ open. 2016;6(12):e011458.

30. Sendeku FW, Azeze GG, Fenta SL. Perinatal asphyxia and its associated factors in Ethiopia: a systematic review and meta-analysis. BMC Pediatr. 2020;20(1):1-11.

31. DerSimonian R, Laird N. Meta-analysis in clinical trials. Control Clin Trials. 1986;7(3):177-88

32. Huedo-Medina TB, Sánchez-Meca J, Marín-Martínez F, Botella J. Assessing heterogeneity in meta-analysis: Q statistic or 12 index? Psychol Methods. 2006;11(2):193-206.

33. Higgins JP, Altman DG. Assessing risk of bias in included studies. In: Higgins JP, Green S, editors. Cochrane handbook for systematic reviews of interventions. 2008. https://doi.org/10.1002/9780470712184.ch8.

34. Egger M, Davey-Smith G, Altman D. Systematic reviews in health care: meta-analysis in context. Hoboken: John Wiley \& Sons; 2008.

35. Fantu S, Segni H, Alemseged F. Incidence, causes and outcome of obstructed labor in Jimma University Specialized Hospital. Ethiop J Health Sci. 2010:20:145-51.

36. Gudina AT, Abebe TW, Gebremariam FA, Guto GJ. Magnitude of obstructed labor and associated risk factors among mothers come for delivery service in Adama Hospital Medical College Oromia Regional State, Central Ethiopia. J Gynecol Obstet. 2016;4(3):12-6.

37. Henok A, Asefa A. Prevalence of obstructed labor among mothers delivered in Mizan-Aman General Hospital, South West Ethiopia: a retrospective study. J Womens Health Care. 2015:4:2167.

38. Berhane $Y$, Hogberg U. Prolonged labour in rural Ethiopia: a community based study. Afr J Reprod Health. 1999;3(2):33-9.

39. Sisay S, Endris M, Genet Y, Mohammed M. Assessment of magnitude and factors contributing to obstructed labor among mothers delivered in Mizan-Tepi University Teaching Hospital, Bench-Maji Zone, SNNPR, Ethiopia 2017. Glob J Reprod Med. 2017;2(4):65-71.

40. Wube TT, Demissie BW, Assen ZM, Gelaw KA, Fite RO. Magnitude of obstructed labor and associated factors among women who delivered at public hospitals of Western Harerghe Zone, Oromia, Ethiopia. Clin Med Res. 2018;28(7):135.

41. Gaym A. Obstructed labor at a district hospital. Ethiop Med J. 2002;40(1):11-8.

42. Abdo RA, Halil HM. Magnitude and factors associated with obstructed labor among women delivered at Halaba Kulito Primary Hospital, Halaba Special District Southern Ethiopia. J Women's Health Care. 2019;8(453):2167-420. 
43. Ukke GG, Gudayu TW, Gurara MK, Amanta NW, Shimbre MS. Fetomaternal outcomes in obstructed labor in Suhul General Hospital, North Ethiopia. Int J Nurs Midwifery. 2017;9(6):77-84.

44. Abraham W, Berhan Y. Predictors of labor abnormalities in university hospital: unmatched case control study. BMC Pregnancy Childbirth. 2014;14:256.

45. Addisu D, Mekie M, Melkie A, Yeshambel A. Burden of obstructed labor in Ethiopia: asystematic review and meta-analysis. Midwifery. 2021:95:102930. https://doi.org/10.1016/j.midw.2021.102930.

46. Dile M, Demelash H, Meseret L, Abebe F, Adefris M, Goshu YA, et al. Determinants of obstructed labor among women attending intrapartum care in Amhara Region, Northwest Ethiopia: a hospital-based unmatched case-control study. Womens Health. 2020;16:1745506520949727.

47. Wonde TE, Mihretie A. Maternofetal outcomes of obstructed labor among women who gave birth at general hospital in Ethiopia. BMC Res Notes. 2019;12:128. https://doi.org/10.1186/s13104-019-4165-8.

48. Wonde TE, Mihretie A. Maternofetal outcomes of obstructed labor among women who gave birth at general hospital in Ethiopia. BMC Res Notes. 2019:12(1):128

49. World Health Organization. The World health report: make every mother and child count. Geneva: World Health Organization; 2005.

50. Chhabra S, Gandhi D, Jaiswal M. Obstructed labour-a preventable entity. J Obstet Gynaecol . 2000;20(2):151-3.

51. Memon S, Qazi RA, Malhi P, Khushk IA. Pattern of obstructed labour at a public sector university hospital of Sindh, Pakistan. J Liaquat Univ Med Health Sci. 2009:8:60-4

52. Ozumba BC, Uchegbu H. Incidence and Management of Obstructed Labour in Eastern Nigeria. Aust N Z J Obstet Gynaecol. 1991:31(3):213-6.

53. Kabakyenga JK, Östergren PO, Turyakira E, Mukasa PK, Pettersson KO. Individual and health facility factors and the risk for obstructed labour and its adverse outcomes in south-western Uganda. BMC Pregnancy Childbirth. 2011;11:73.

54. Revicky V, Muralidhar A, Mukhopadhyay S, Mahmood T. A case series of uterine rupture: lessons to be learned for future clinical practice. J Obstet Gynaecol India. 2012;62(6):665-73.

55. Yemane Y, Gizaw WJHSJ. Assessment of the associated factors, management and complications of uterine rupture at Mizan-Tepi University Teaching Hospital, Mizan-Aman Town, Bench-Maji Zone, Snnprs, South West Ethiopia, 2016/17: a case control study. Health Sci J. 2017. https:// doi.org/10.21767/1791-809X.1000511.

56. Chibber R, Elsaleh E, Fadhli RA, Jassar WA, Harmi F, Medicine N. Uterine rupture and subsequent pregnancy outcome-how safe is it? A 25-year study. J Matern Fetal Neonatal Med. 2010;23(5):421-4.

57. Islam JA, Ara G, Choudhury FR. Risk factors and outcome of obstructed labour at a tertiary care hospital. J Shaheed Suhrawardy Med Coll. 2012:4(2):43-6.
58. Bailey PE, Awoonor-Williams JK, Lebrun V, Keyes E, Chen M, Aboagye $P$, et al. Referral patterns through the lens of health facility readiness to manage obstetric complications: national facility-based results from Ghana. Reprod Health. 2019;16(1):19.

59. Musaba MWNG, Barageine JK, Weeks A, Nankabirwa V, Wamono F, et al. Risk factors for obstructed labour in Eastern Uganda: a case control study. PLoS ONE. 2020;15:e0228856.

60. Uganda Bureau of Statistics (UBOS) and Macro International Inc. Uganda Demographic and Health Survey 2006. Calverton, Maryland, USA: UBOS and Macro International Inc; 2007.

61. Muleta M. Socio-demographic profile and obstetric experience of fistula patients managed at the Addis Ababa Fistula Hospital. Ethiop Med J. 2004;42(1):9-16.

62. Central Statistical Agency (CSA) [Ethiopia] and ICF. Ethiopia Demographic and Health Survey 2016. Addis Ababa, Ethiopia, and Rockville, Maryland, USA: CSA and ICF; 2016.

63. Memon S, Qazi RA, Malhi P, Khushk IA. Pattern of obstructed labour at a public sector university hospital of Sindh, Pakistan. J Liaquat Univ Med Health Sci. 2009;8:60-4.

64. Roa L, Caddell L, Ganyaglo G, Tripathi V, Huda N, Romanzi L, et al. Toward a complete estimate of physical and psychosocial morbidity from prolonged obstructed labour: a modelling study based on clinician survey. BMJ Global Health. 2020;5(7):e002520.

65. Nyfløt LT, Stray-Pedersen B, Forsén L, Vangen S. Duration of labor and the risk of severe postpartum hemorrhage: a case-control study. PLoS ONE. 2017;12(4):e0175306

66. Le Ray C, Fraser W, Rozenberg P, Langer B, Subtil D, Goffinet F. Duration of passive and active phases of the second stage of labour and risk of severe postpartum haemorrhage in low-risk nulliparous women. Eur J Obstet Gynecol Reprod Biol. 2011;158(2):167-72.

67. Kadowa I. Ruptured uterus in rural Uganda: prevalence, predisposing factors and outcomes. Singapore Med J. 2010;51(1):35.

68. Hofmeyr GJ, Say L, Gülmezoglu AM. WHO systematic review of maternal mortality and morbidity: the prevalence of uterine rupture. BJOG. 2005;112(9):1221-8.

69. Khan KS, Wojdyla D, Say L, Gülmezoglu AM, Van Look PF. WHO analysis of causes of maternal death: a systematic review. Lancet. 2006:367(9516):1066-74.

\section{Publisher's Note}

Springer Nature remains neutral with regard to jurisdictional claims in published maps and institutional affiliations.
Ready to submit your research? Choose BMC and benefit from:

- fast, convenient online submission

- thorough peer review by experienced researchers in your field

- rapid publication on acceptance

- support for research data, including large and complex data types

- gold Open Access which fosters wider collaboration and increased citations

- maximum visibility for your research: over 100M website views per year

At BMC, research is always in progress.

Learn more biomedcentral.com/submissions 